Short Communication

\title{
'You have 45 minutes, starting from now': helping students develop their exam essay skills
}

Chris Willmott

Department of Biochemistry, Henry Wellcome Building, University of Leicester

Keywords: Exam essays, peer marking, key skills, training

In recent years academics have commonly bemoaned the lack of essaywriting ability exhibited by their students. Whether or not the halcyon era in which undergraduates routinely knew how to construct a persuasive essay ever truly existed, it is certainly the case that contemporary students can benefit from advice on preparation of a long-format written answer.

In many ways, the need for training is most apparent in the context of exam essays, and yet it is this aspect of their work on which students are least likely to receive guidance and/or feedback. By their very nature, examinations tend to take place at or near the end of a module. For very practical reasons, therefore, it is not usually possible to take students analytically through their exam essays. Coupled with this, there may be a certain reticence to share annotated scripts with their authors for fear of hours lost whilst they haggle for additional credit.

Over the past six years, we have been running an exercise on writing exam essays as part of our first year Key Skills programme for students of Medical Biochemistry and, latterly, Medical Genetics and Medical Physiology. This short article offers practical advice on the selection of material and the construction of the activities.

The exam essays component of the module runs for three sessions. In the first, students are given the opportunity to read and rank a set of genuine essays written by an earlier cohort. This is followed by the students doing a timed essay under exam conditions. In the third phase, the group read and make comments on the essays written by their peers. The essays are then collected back in and passed to tutors for summative assessment.

\section{Choice of material on which to base the exercise}

A number of important considerations go into the selection of the essays. Firstly, the subject matter needs to be a topic with which the students have at least a passing familiarity. In our case, we have used a question about haemoglobin and allostery, to which these students have had exposure during the previous term. 
Secondly, an appropriate number and range of essays should be used. I would recommend a total of six essays as being optimum for the exercise. This allows for a suitable spread of quality and, in practical terms, represents a number that students can read thoroughly in a 45-50 minute period without becoming bored. We tried using ten essays one year, but they took too long to read and some of the differences between the marks awarded started to come down to quite subtle nuances, beyond the likely knowledge of the participants.

It is also helpful if the essays used do not fall into a pattern of 'the longer the better'. Clearly there will be a general correlation between length and the number of salient points made, but it is helpful if the collection includes at least one long-but-vacuous and/or short-and-pithy example.

Thirdly, there is the decision whether to use handwritten or re-typed scripts. For reasons I will elaborate below, I would strongly recommend using photocopies of the original answers. Presentation of material, both in terms of layout and handwriting, can have a significant bearing on the mark awarded. At the extreme end of the spectrum, there is the risk that an illegible essay cannot gain the credit due for its content. It is interesting in this regard that the essay which achieved the highest mark when originally marked (see Table 1) has actually been rated by two of the student groups as the worst. When asked to justify this decision, they answered that they could not read it.

Table 1 Average ranking of essay as decided by student groups in 2005 and 2006 (n=16) compared with real rank order when marked by staff

\begin{tabular}{|l|l|l|l|l|l|l|}
\hline Anonymised essay code & a & b & c & d & e & f \\
\hline Genuine mark awarded & 62 & 58 & 68 & 45 & 80 & 52 \\
\hline Real ranking position & 3 & 4 & 2 & 6 & 1 & 5 \\
\hline Ranking by students & 3 & 4 & 1 & 6 & 2 & 5 \\
\hline
\end{tabular}

True, the handwritten essays will have had to go through two rounds of photocopying (once to preserve the original, a second time to remove the annotations and comment made by the genuine markers of the work) and this does not improve the legibility, but the importance of writing clearly is, nevertheless, a lesson that would not be conveyed if re-typed essays were used. It is worth noting two further points on this matter. If a number of essays fit the other criteria for inclusion in a similar exercise, those written in black ink will offer better reproduction after the double-photocopying than those written in blue ink or pencil. Additionally, it is important that you retain a complete set of marker's comments to inform the feedback at the end of the task.

A final consideration in the selection of material concerns whether or not we have legitimate right to use students' work in this way. A contributor to the Writing Development in Higher Education discussion board raised this query after I described a pilot version of this exercise on that list (see Willmott (2002) 
and subsequent discussion). To guard against any such difficulties, I selected a second set of essays and obtained written permission from the original student authors to use their answers, on the understanding that all identifiers would be removed, thereby circumventing any potential problem.

\section{Organisation of sessions}

Armed with multiple sets of six anonymised essays, I have run the first session in the following way. This phase of the module is introduced, both by noting the importance placed by universities on essays under exam conditions, and by talking through the standard marking criteria used by the School of Biological Science for examination essays (see Appendix). The specific question addressed in the anonymised scripts and the original mark scheme should be explained. The students are then invited to rank the essays from 'best' to 'least good', making a note, on a separate sheet, of the strengths and weaknesses of each answer. I divide the class (approximately 80 in total) into groups of eight to ten and provide each group with two sets of six essays to ensure that there are plenty of scripts available. Additionally, they are told that, on this occasion, none of the essays received the same mark. I also emphasise that 45 minutes are provided for this activity and that they should endeavour to read each of the essays carefully in that time, before coming up with a rank order decided by their group as a whole.

It is worth noting, in passing, that the room layout is very important for smooth running of both this activity and the corresponding work in the third tutorial. Efficient discussion of the essays requires that the students can be sitting around tables rather than working in a tiered lecture theatre.

Having allowed plenty of time for reading and discussion, the ranking determined by each group is collated into a table and the 'real' order decided by the staff marking the original submission is revealed. Strengths and weaknesses of each essay are discussed and used as a route into more general discussion of good exam essay practice, including the importance of a plan, legibility and structure. Finally, students are introduced to the question on which they are to write a timed essay in the next session. In our case, the essay is on meiosis, a subject chosen to dovetail with the content of a concurrent genetics module.

During the second session, a week after the first, the students write their essay. To add to the 'authenticity' of the experience we use genuine university examination answer booklets and carry out the process in one of the rooms used for exams. 45 minutes are allowed; the same time that they would have if asked to write four essays during a three hour exam.

In the final session of the series, students get the opportunity both to see essays written by their peers but also to receive peer-feedback on their own work (albeit with the latter retained by staff until after the formal assessment and return of the essays). In previous years, I have spent time between the writing of the essays and the peer-review stage sorting the scripts, which of course are still identified by candidate number rather than name, into the work groups of their author and then deciding which other group of students should 
read their work. Latterly, however, I have abandoned this stage since it works equally well to distribute essays randomly to each table of students, ask them to check that none of the essays on the table belongs to any of them, and then redistribute any which have ended up in proximity to their owner.

Having distributed the essays, I work through a model answer, and identify some common errors (e.g. the absence of a concluding section, and/or the failure to title and label figures). The students are then invited to read, and offer comments on, the essays written by their contemporaries. I stress that, since somewhere in the room someone is doing the same to their work, it is important than only constructive and sensible feedback is given. It is gratifying that the students do indeed enter into the process in the right spirit, and the advice given by peers is often very pertinent and helpful. Student comments are not written directly onto the scripts; a piece of coloured paper is provided to accompany each essay and the students are encouraged to write the candidate number of the corresponding essay on the top of the paper and circulate the paper with the essays so that they can add comments about the same piece in turn.

\section{Evaluation and final comments}

Over the years, this exercise has consistently been appreciated by the participants (see Box 1 for example comments).

Box 1 Examples of student feedback on exam essay training sessions

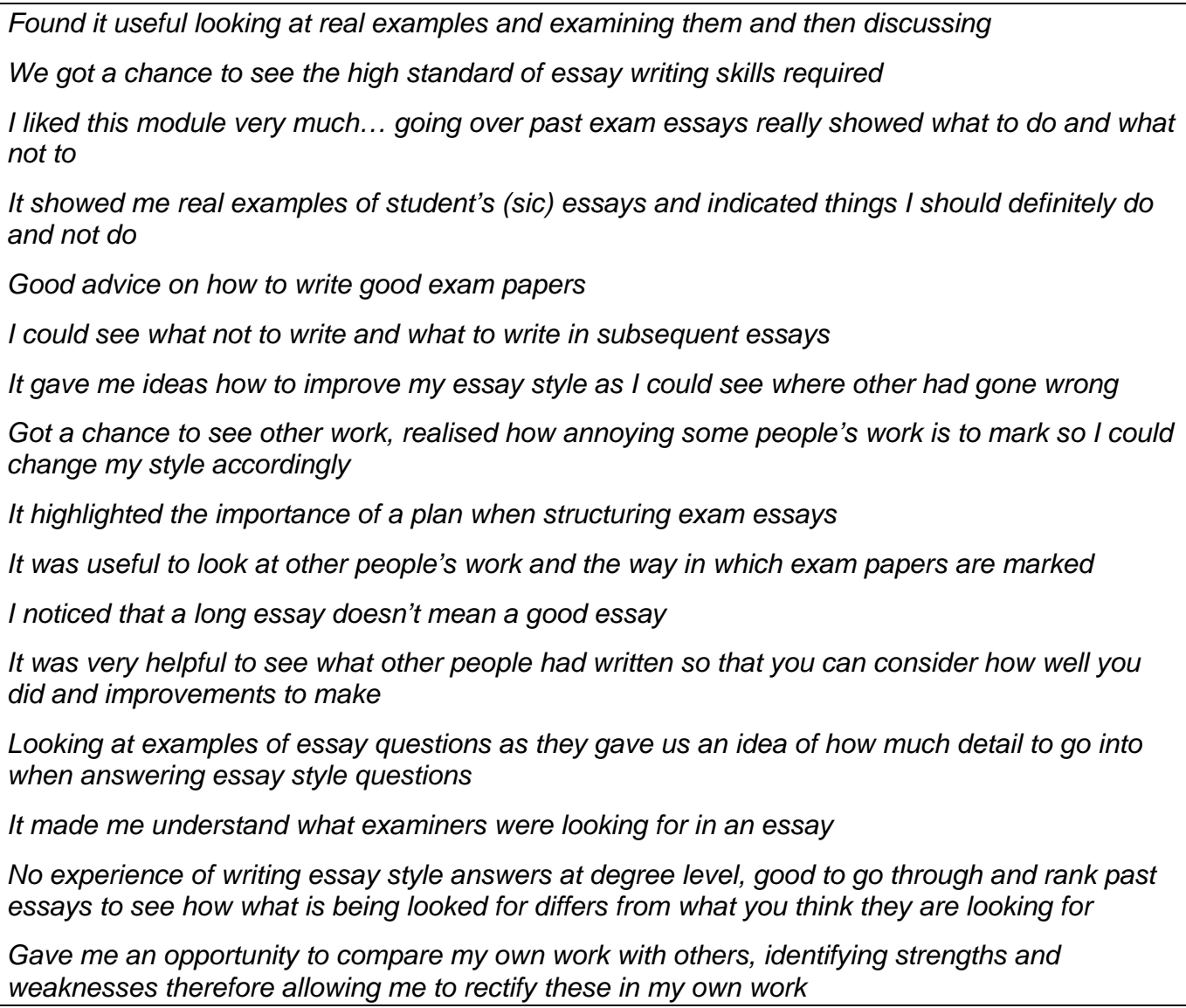


Not only do the students get the opportunity to see real work produced by their peer group, which in itself is a relatively rare event, they also get an insight into the complexity of the marking process. Table 1 summarises the average rank order as decided by 16 student groups 'marking' the essays in 2005 and 2006. It should be evident that there is generally a good correlation between the order assigned by the students and the 'real' order determined when staff originally marked the essays. The key difference is that the strongest essay has only come out second in the overall student list. As hinted above, this is at least partially attributable to the fact that difficulties with legibility led two group to give this essay the lowest position in their list.

Essay writing, particularly under the constraints of exam conditions, is an unnatural activity and one upon which contemporary undergraduates may never have received any formal advice. We have conducted these activities in the context of a stand-alone skills module, albeit with deliberate crossreference to a concurrent genetics module. However, there is no reason why a series of three sessions on essay writing, as described here, could not be incorporated directly within a subject-specific unit.

Corresponding author: Chris Willmott, Department of Biochemistry, Henry Wellcome Building, University of Leicester, Leicester, LE1 9HU Telephone: 0116229 7046 e-mail: cjrw2@le.ac.uk

\section{References}

Willmott (2002) Re: example assignment projects, contribution to the Writing Development in Higher Education discussion list, available at www.jiscmail.ac.uk/cgi-bin/webadmin?A2=ind02\&L=WRITING-DEV-HE\&P=R9208\&I=-3 (accessed 29 ${ }^{\text {th }}$ March 2007) 